
\title{
R Research Sourere \\ Experimental study on proportioning and properties of cemented filling material with a large mass ratio of construction demolition waste
}

Yewu Bi ( $\sim$ byw@mail.usth.edu.cn )

China University of Mining and Technology - Beijing Campus https://orcid.org/0000-0003-3584-9103

\section{Weixin Chen}

Heilongjiang University of Science and Technology

\section{Yucheng Huang}

China University of Mining and Technology-Beijing

\section{Research}

Keywords: Large mass ratio, cemented filling materials, orthogonal test, properties analysis

Posted Date: May 23rd, 2020

DOI: https://doi.org/10.21203/rs.3.rs-29622/v1

License: (1) This work is licensed under a Creative Commons Attribution 4.0 International License.

Read Full License 


\title{
Experimental study on proportioning and properties of cemented filling material with a large mass ratio of construction demolition
}

\author{
waste \\ Yewu $\mathrm{Bi}^{1,2 *}$, Weixin $\mathrm{Chen}^{3}$, Yucheng Huang ${ }^{1}$
}

(1.School of Energy and Mining Engineering, China University of Mining and Technology

-Beijing, Beijing 100083, China, 2.School of Safety Engineering, Heilongjiang University of Science and Technology, Harbin 150022, China, 3.School of Mining Engineering, Heilongjiang University of Science and Technology, Harbin 150022, China)

*Corresponding author. Tel: +86 1880042 1021, E-mail: byw@mail.usth.edu.cn

\begin{abstract}
Supply of cheap and abundant raw materials is a key factor in reducing the cost of cemented filling materials. To solve this problems of the high cost of cemented filling materials and insufficient sources of raw materials, an experimental study on cemented filling material with a large mass ratio of construction demolition waste was performed. A large amount of recycled aggregate of construction demolition waste was added to cemented material to prepare a high concentration slurry, from which the influences of aggregate/cement mass ratio, admixture/cement mass ratio, water/solid mass ratio, recycled aggregate gradation and mud content of recycled aggregate on slump, setting time and compressive strength of cemented filling material with a large mass ratio of construction demolition waste were analysed via the orthogonal test method and regression equation analysis. Finally, an industrial formula for cemented filling material with a large mass ratio of construction demolition waste was determined, and the mechanical and microscopic properties were analysed. The results indicate that the industrial formula with an aggregate/cement mass ratio of 3.0, an admixture/cement mass ratio of $1.5 \%$, a water/solid mass ratio of 0.35 , a recycled aggregate gradation of 40:30:15:15, a mud content of recycled aggregate of $0 \sim 4 \%$ and a mass ratio of construction demolition waste to solid material of $75 \%$ exhibits the properties of rapid strength growth and high residual strength, and can be applied in underground coal mines conditions.
\end{abstract}

Keywords: Large mass ratio, cemented filling materials, orthogonal test, properties analysis

\section{Introduction}

The exploitation of coal resources has made a great contribution to economic and social development in China but has also introduced many problems, especially the destruction of ecological environments and mine disasters. The most prominent problem is the surface subsidence and groundwater loss in underground coal mines. To solve these problems, Chinese scholars have performed extensive research and practice, formed a unique special coal mining technology system in China and have gradually developed towards "green", "safe" and "harmless" practices (Kang et al. 2019). The research has proven that filling mining is an effective way to realize "green", "safe" and "harmless" mining in underground coal mines (Wang 2013). At present, gangue, paste, high water, ultra-high water, and high concentration cemented material are the main filling materials in underground coal mines of China; however, the high cost of filling materials and the lack of raw materials are the key factors restricting the large-scale deployment of filling mining (Hu 2012; Jia et al. 2012; Yang et al. 2015; Cheng et al. 2018; Liu et al. 2020).With the acceleration of urban construction, the amount of construction demolition waste in China is also 
increasing. At present, the amount of construction demolition waste in China accounts for 30 $40 \%$ of the total amount of urban waste (Li 2018; Wang et al. 2018; Huang et al. 2018). According to statistical data, the amount of newly generated construction demolition waste in China is more than 1 billion tons each year ( $\mathrm{Lu} \mathrm{2018;} \mathrm{Xu} \mathrm{et} \mathrm{al.} \mathrm{2019).} \mathrm{However,} \mathrm{the} \mathrm{resource} \mathrm{utilization} \mathrm{ratio} \mathrm{of}$ construction demolition waste is less than $10 \%$ (Chen et al. 2018). If construction demolition waste is not used, it will not only seriously damage the ecological environment but also endanger human health and public safety. Therefore, the conversion of construction demolition waste into recycled aggregate, a large mass ratio of which is added into cemented filling material that satisfy the requirements of field applications, can not only effectively solve the problems of the high cost of cement filling materials and scarcity of raw materials but also realize resource conservation and ecological environment protection to achieve green, low-carbon, recyclable, and sustainable development. In recent years, many scholars in academia have studied recycled aggregates of construction demolition waste as filling materials in underground coal mines and have made some progress. Liu et al. (2012) proposed that it is technically feasible to use construction demolition waste as paste filling aggregate in coal mines. Liu et al. (2017) analysed the influences of slurry mass concentration, the proportion of cemented agent and recycled aggregates on the performance index of the filling paste as determined by the orthogonal test method. Taking construction waste as the aggregate, and coarse fly ash as the cemented material, they found that the quality concentration of the paste and the ratio of ash to material were the main factors affecting the stratification degree and the compressive strength of the filling body. Liu et al. also determined the optimal proportion of filling materials for construction demolition waste paste. Zhang et al. (2014) proposed that paste made of three types of construction demolition waste from different sources met the basic requirements of paste filling in coal mines and that concrete frame construction demolition waste paste was more suitable for coal mine filling materials. Zhang et al. (2014) performed the proportioning test and pipeline transportation test of paste filling materials using a laboratory simulation system and analysed the basic performance and the rheological properties of the construction demolition waste-fly ash paste filling materials. Jiang et al. (2015) presented the optimal proportion of paste filling materials with construction demolition waste, natural sand, cement and fly ash as component materials using the orthogonal test. Chen et al. (2015) determined the mix of construction waste and fly ash-based cemented filling materials by the orthogonal test. The filling material has the characteristics of strong plasticity, high residual strength and quick setting. Qiu et al. (2016) analysed the influence of particle size of different base materials on the strength of construction demolition waste slurry backfill material. Han et al. (2018) analysed the apparent density, stacking density, water absorption and crushing index of the recycled aggregate of construction demolition waste, and studied the influence of the recycled aggregate of construction demolition waste on the performance of mine filling paste. Li et al. (2019) determined the optimal proportion of construction demolition waste filling materials by the orthogonal test and analysed the mechanical properties of the construction demolition waste aggregate-coarse fly ash-based cemented filling body. Liu et al. (2020) determined that construction demolition waste is a suitable filling material for underground coal mines and analysed the aggregate distribution, compressive strength and mesostructure of cemented paste backfill prepared from construction demolition waste.

Based on the above analysis, the study of the basic properties of cemented filling material with a large mass ratio of construction demolition waste has rarely been performed in the 
academic circle. Therefore, the study of the industrial formula of cemented filling material with a large mass ratio of construction demolition waste and its properties determined by the orthogonal test and regression equation analysis method are described herein.

\section{Materials and methods}

The experimental materials included cement, admixture and recycled aggregate of construction demolition waste. The cement was Huding 32.5 fly ash composite Portland cement manufactured by Luding Group Harbin Cement Co., Ltd. of China and it met the standard of general Portland cement (GB 175-2007) by the ex-factory inspection. The admixture was composed of the accelerator, retarder, early strength agent, thickener and pumping agent (in a mass ratio of 6:1:3:2:1). The admixture conformed to GB 8076-2008 concrete admixture specification. The cement and admixture were raw materials of cemented materials. The construction demolition waste processed by multiple crushing processes was used as recycled aggregate, the particle size of which was approximately $20 \mathrm{~mm}$, as shown in Fig. 1.
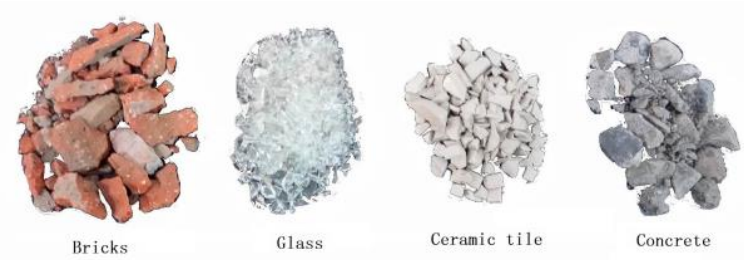

Fig. 1 The recycled aggregate of construction demolition waste

Based on extensively reported basic experiments (Chen et al. 2014; Chen et al. 2015; Chen et al. 2015; Chen et al. 2019), the mass ratio of recycled aggregate to cement (aggregate/cement mass ratio) was expressed as $\mathrm{A}$, the mass ratio of admixture to cement (admixture/cement mass ratio) was expressed as $\mathrm{B}$, the mass ratio of water to solid material (water/solid mass ratio) was expressed as $\mathrm{C}$, the recycled aggregate gradation was expressed as $\mathrm{D}$, and the mud content of recycled aggregate was expressed as E. A, B, C, D, and E were taken as the experimental factors, L16 (45) was chosen as the orthogonal table, and four levels were taken for each factor, among which the mass ratio of gradation schemes 1,2,3 and 4 (representing particle sizes ranging from 0 to $5 \mathrm{~mm}, 5$ to $10 \mathrm{~mm}, 10$ to $20 \mathrm{~mm}$, and 20 to $31.5 \mathrm{~mm}$, respectively) were 25:25:25:25, 20:30:30:20, 30:30:20:20, and 40:30:15:15, respectively. The factors and levels of the orthogonal experiment are shown in Table 1.

Table 1 Levels and factors of the orthogonal test

\begin{tabular}{cccccc}
\hline & \multicolumn{5}{c}{ Factors } \\
\cline { 2 - 5 } Levels & $\mathrm{A}$ & $\mathrm{B}$ & $\mathrm{C}$ & $\mathrm{D}$ & $\mathrm{E}$ \\
\hline 1 & 1.5 & $0.5 \%$ & 0.25 & 1 & $1.0 \%$ \\
2 & 2.0 & $1.0 \%$ & 0.30 & 2 & $2.0 \%$ \\
3 & 2.5 & $1.5 \%$ & 0.35 & 3 & $3.0 \%$ \\
4 & 3.0 & $2.0 \%$ & 0.40 & 4 & $4.0 \%$ \\
\hline
\end{tabular}

\section{Results and discussion}

\subsection{Experimental results}


The experimental scheme was listed according to the orthogonal experimental levels and factors. A slurry of cemented material was prepared first, then the recycled aggregate was mixed with it to obtain a slurry of cemented filling material with a large mass ratio of construction demolition waste. One part of the slurry was poured into the slump bucket to measure its initial slump, whereas another part was poured into the penetration resistance meter to measure the initial setting time. The remainder of the slurry were poured into a square plastic test mould with dimensions of $70.07 \mathrm{~mm} \times 70.07 \mathrm{~mm} \times 70.07 \mathrm{~mm}$, in which the uniaxial compressive strength was measured after standard curing for $7 \mathrm{~d}$. The experimental scheme and results are shown in Table 2.

Table 2 Scheme and results of the orthogonal test

\begin{tabular}{|c|c|c|c|c|c|c|c|c|}
\hline \multirow{2}{*}{$\begin{array}{c}\text { Test } \\
\text { number }\end{array}$} & \multicolumn{5}{|c|}{ Factor } & \multirow{2}{*}{$\begin{array}{l}\text { Initial } \\
\text { slump } \\
/ \mathrm{mm}\end{array}$} & \multirow{2}{*}{$\begin{array}{c}\text { Initial } \\
\text { setting } \\
\text { time/mi } \\
n\end{array}$} & \multirow{2}{*}{$\begin{array}{l}\sigma_{c, 7 d} \\
/ \mathrm{MPa}\end{array}$} \\
\hline & A & B & $\mathrm{C}$ & $\mathrm{D}$ & E & & & \\
\hline 1 & 1.5 & $0.5 \%$ & 0.25 & 1 & $1.0 \%$ & 78 & 83 & 2.77 \\
\hline 2 & 1.5 & $1.0 \%$ & 0.30 & 2 & $2.0 \%$ & 88 & 74 & 3.29 \\
\hline 3 & 1.5 & $1.5 \%$ & 0.35 & 3 & $3.0 \%$ & 100 & 64 & 3.19 \\
\hline 4 & 1.5 & $2.0 \%$ & 0.40 & 4 & $4.0 \%$ & 130 & 62 & 4.00 \\
\hline 5 & 2.0 & $0.5 \%$ & 0.30 & 3 & $4.0 \%$ & 99 & 92 & 2.90 \\
\hline 6 & 2.0 & $1.0 \%$ & 0.25 & 4 & $3.0 \%$ & 134 & 90 & 4.25 \\
\hline 7 & 2.0 & $1.5 \%$ & 0.40 & 1 & $2.0 \%$ & 147 & 85 & 3.09 \\
\hline 8 & 2.0 & $2.0 \%$ & 0.35 & 2 & $1.0 \%$ & 156 & 60 & 4.00 \\
\hline 9 & 2.5 & $0.5 \%$ & 0.35 & 4 & $2.0 \%$ & 187 & 120 & 3.01 \\
\hline 10 & 2.5 & $1.0 \%$ & 0.40 & 3 & $1.0 \%$ & 193 & 105 & 2.77 \\
\hline 11 & 2.5 & $1.5 \%$ & 0.25 & 2 & $4.0 \%$ & 182 & 91 & 3.00 \\
\hline 12 & 2.5 & $2.0 \%$ & 0.30 & 1 & $3.0 \%$ & 198 & 82 & 2.01 \\
\hline 13 & 3.0 & $0.5 \%$ & 0.40 & 2 & $3.0 \%$ & 211 & 146 & 0.50 \\
\hline 14 & 3.0 & $1.0 \%$ & 0.35 & 1 & $4.0 \%$ & 217 & 110 & 0.20 \\
\hline 15 & 3.0 & $1.5 \%$ & 0.30 & 4 & $1.0 \%$ & 223 & 119 & 0.87 \\
\hline 16 & 3.0 & $2.0 \%$ & 0.25 & 3 & $2.0 \%$ & 230 & 100 & 1.02 \\
\hline
\end{tabular}

\subsection{Regression analysis}

(1) Regression analysis of the slump results

Regression analysis was conducted on the slump result of the initial slurry of cemented filling material with a large mass ratio of construction demolition waste. The normal probability distribution diagram of the slump of the initial slurry (as shown in Fig. 2) and the regression coefficient of factors $\mathrm{A} \sim \mathrm{E}$ were obtained. The optimal regression equation is as follows:

$$
\mathrm{Y}_{\text {Initial slump }}=-134.4+84.0 \mathrm{X}_{\mathrm{A}}+2185 \mathrm{X}_{\mathrm{B}}+112 \mathrm{X}_{\mathrm{C}}+2.2 \mathrm{X}_{\mathrm{D}^{-}}-187.5 \mathrm{X}_{\mathrm{E}}
$$




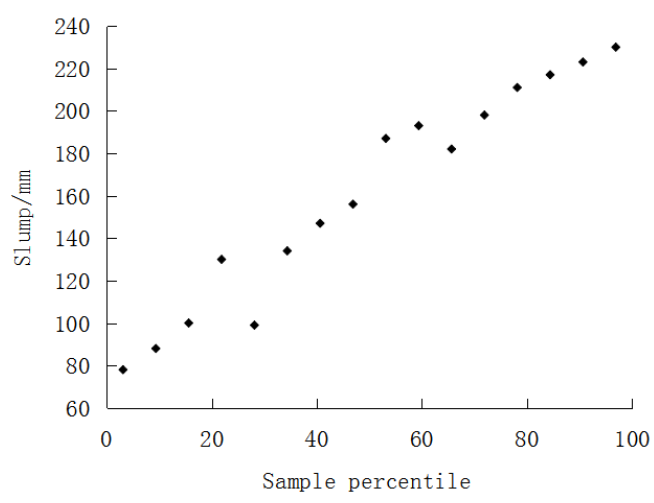

Fig. 2 Normal probability distribution diagram of the slump of the initial slurry

According to the variance analysis of the experimental results of the slump of the initial slurry, the F-value is 51.9 and the p-value is 0.005 . The F-value is much larger than the p-value, thus the model has statistical meaning. From the regression equation, all of the factors, except for factor E, have an increasing effect on the slump of the initial slurry, with factor B exhibiting the most obvious effect. The primary and secondary order of influencing factors on the initial slump of the slurry is thus B, E, C, A and D.

(2) Regression analysis of initial setting time results

Regression analysis was conducted on the results of the initial setting time of cemented filling material with a large mass ratio of construction demolition waste. The normal probability distribution diagram of the initial setting time of the slurry (as shown in Fig. 3) and the regression coefficient of factors $\mathrm{A} \sim \mathrm{E}$ were obtained. The optimal regression equation is as follows:

$$
\mathrm{Y}_{\text {Initial setting time }}=13.1+32.4 \mathrm{X}_{\mathrm{A}}-2155 \mathrm{X}_{\mathrm{B}}+44.5 \mathrm{X}_{\mathrm{C}}+2.1 \mathrm{X}_{\mathrm{D}}-82.5 \mathrm{X}_{\mathrm{E}}
$$

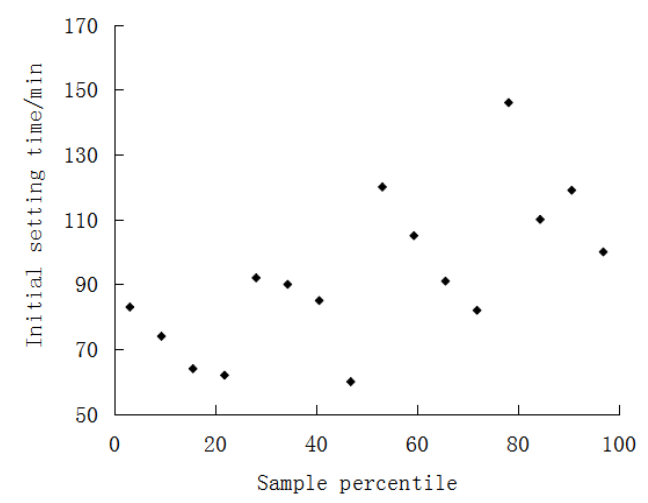

Fig. 3. Normal probability diagram of initial setting time

According to the variance analysis of the experimental results of the initial setting time of the slurry, the F-value is 28.9 and the p-value is 0.07 . The F-value is much larger than the p-value, thus the model has statistical meaning. From the regression equation, all of the factors, except for factors $\mathrm{B}$ and $\mathrm{E}$, have a quick setting effect on cemented filling material, with factor $\mathrm{C}$ exhibiting the most obvious quick setting effect. The primary and secondary order of influencing factors of the initial setting time of the slurry is thus B, E, C, A and D.

(3) Regression analysis of the compressive strength results

Regression analysis was conducted on the compressive strength results of cemented filling material with a large mass ratio of construction demolition waste for $7 \mathrm{~d}$. The normal probability distribution diagram of the compressive strength of cemented filling material for $7 \mathrm{~d}$ (as shown in 
Fig. 4) and the regression coefficient of factors $A \sim E$ were obtained. The optimal regression equation is as follows:

$$
\mathrm{Y}_{\sigma_{c, 7 d}}=6.6-1.8 \mathrm{X}_{\mathrm{A}}+26.0 \mathrm{X}_{\mathrm{B}}-0.4 \mathrm{X}_{\mathrm{C}}+0.3 \mathrm{X}_{\mathrm{D}}-3.5 \mathrm{X}_{\mathrm{E}}
$$

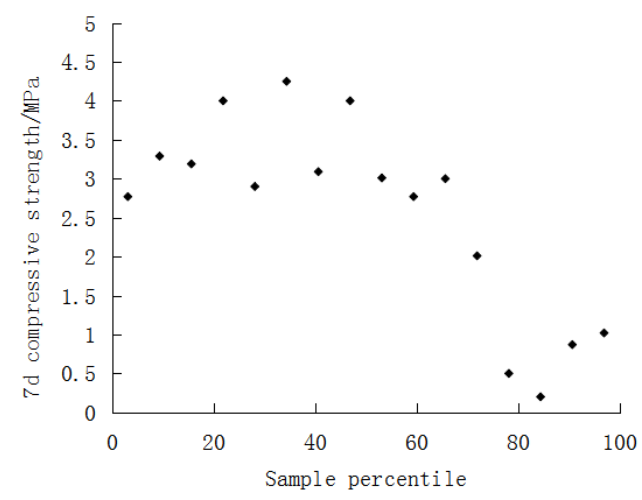

Fig. 4 Normal probability diagram of compressive strength for $7 \mathrm{~d}$

According to the variance analysis of the experimental results of the compressive strength results for $7 \mathrm{~d}$, the F-value is 31.5 and the p-value is 0.41 . The F-value is much larger than the p-value, thus the model has statistical meaning. From the regression equation, all factors, except for factors B and D, can weaken the compressive strength of cemented filling material. The primary and secondary order of influencing factors on the compressive strength of cemented filling material for $7 \mathrm{~d}$ is $\mathrm{B}, \mathrm{E}, \mathrm{A}, \mathrm{C}$ and $\mathrm{D}$.

(4) Comprehensive results analysis

Based on the above analysis, factors B and $\mathrm{E}$ have the most significant influence on the three performance indexes of cemented filling material, namely, the slump, initial setting time and compressive strength, where B is the main influencing factor on all three performance indexes. Therefore, $\mathrm{B}$ is the decisive factor affecting the performance of cemented filling material with a large mass ratio of construction demolition waste, but E, A, C, and D also have a significant impact on the performance of the filling material.

\subsection{Industrial formula of filling material}

The cemented filling material with a large mass ratio of construction demolition waste is a high concentration cemented filling material in which the viscosity and consistency of the slurry are relatively high and continue to increase with time. Therefore, the slurry can only be pumped to the goaf. At present, an increasing number of mines in China will enter a period of deep mining, which, in contrast to shallow mining, will require an increase in filling pipeline as well as the flow time of the slurry in the pipeline. Taking the Qitaihe mining area in Heilongjiang Province of China as an example, the average mining depth of underground coal mines is approximately 400 $\mathrm{m}$, and the length of the filling pipeline is generally under $2000 \mathrm{~m}$. When the average flow rate of the slurry is $0.6 \mathrm{~m} / \mathrm{s}$, the flow time of the slurry in the pipeline is approximately $60 \mathrm{~min}$ (Sun et al. 2002; Huang 2014; Yang 2015). According to the practical experience of cemented filling mining in many mines, the initial slump of the slurry is $190 \sim 210 \mathrm{~mm}$ to ensure the pumping performance of the high concentration cemented filling material. The initial setting time of the filling material should be 80 120 min and the compressive strength over $7 \mathrm{~d}$ should be greater than $2.5 \mathrm{MPa}$ to ensure the rapid form removal after filling with no obvious fracture and subsidence of overlying strata. 
According to the above regression equation and field requirements, and considering the principles of economic and early strength optimization, the industrial formula of cemented filling material with a large mass ratio of construction demolition waste is as follows: A is 3.0, B is 1.5\%, $\mathrm{C}$ is 0.35 , D is No. 4 scheme (40:30:15:15), and $\mathrm{E}$ is $0 \sim 4 \%$. By substituting the regression equation, the initial slump of the material is $191 \sim 198 \mathrm{~mm}$, the initial setting time is $94 \sim 98 \mathrm{~min}$, and the compressive strength of the material for $7 \mathrm{~d}$ is $2.5 \sim 2.7 \mathrm{MPa}$. The properties of this material meet the industrial requirements.

According to the slump test, the penetration resistance test and the uniaxial compression test, the industrial formula exhibits an initial slump of $195 \mathrm{~mm}$, an initial setting time of $95 \mathrm{~min}$ and a compressive strength for $7 \mathrm{~d}$ of $2.5 \mathrm{MPa}$. The experimental results are within the performance range of the industrial formula obtained by the regression equation.

\subsection{Analysis of mechanical properties}

The test block was made according to the industrial formula to analyse the mechanical properties of cemented filling material with a large mass ratio of construction demolition waste and to obtain a full stress-strain curve of each age by a WDS-50A press (as shown in Fig. 5). The stress-strain curve of different ages can be divided into four stages: (1) the compression stage, where the curve is concave up, the curvature of the curve increases gradually with increasing stress, and the increasing value of the stress gradually becomes greater than the increasing value of the strain; (2) the elastic stage, where the strain increases gradually with increasing stress and the relationship between stress and strain is essentially linear, i.e., the slope of the curve remains unchanged; (3) the plastic deformation stage, where the curvature of the curve decreases gradually with increasing stress, and the stress reaches peak strength; and (4) the yield failure stage, where the curvature of the curve increases gradually with increasing stress and the test block shows obvious cracks until complete failure and loss of strength. After yielding, the residual strength is high, which is approximately $60 \sim 80 \%$ of the ultimate strength, thus the filling body has good bearing capacity.

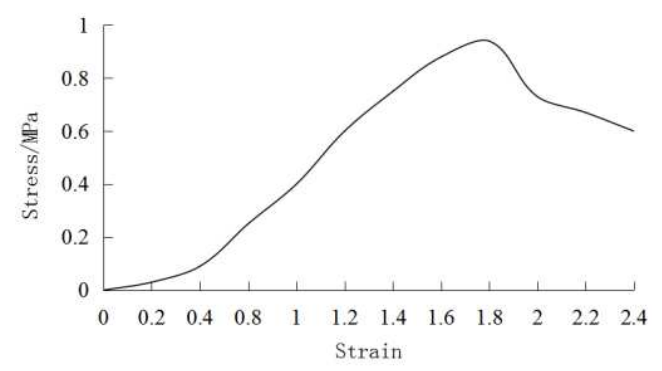

(a) Stress-strain curve of $1 \mathrm{~d}$ age

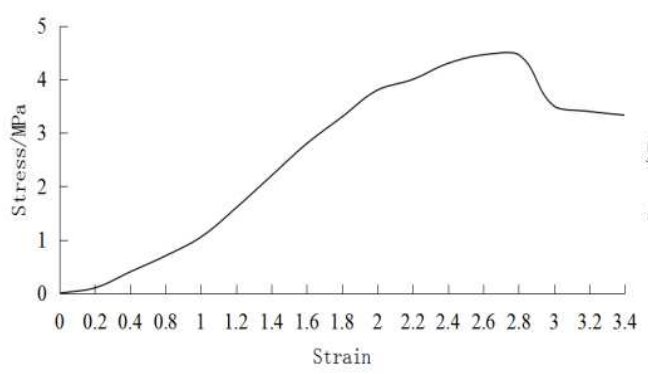

(c) Stress-strain curve of $14 \mathrm{~d}$ age

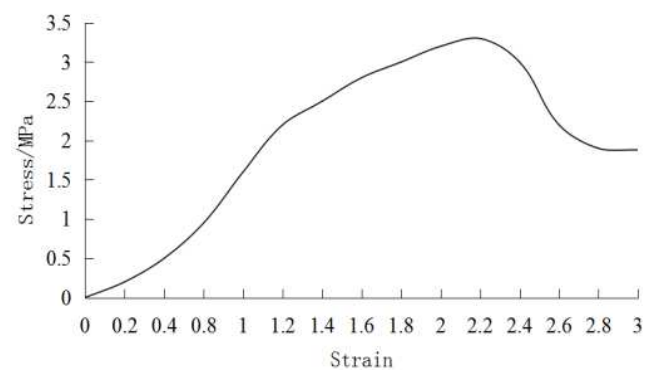

(b) Stress-strain curve of $7 \mathrm{~d}$ age

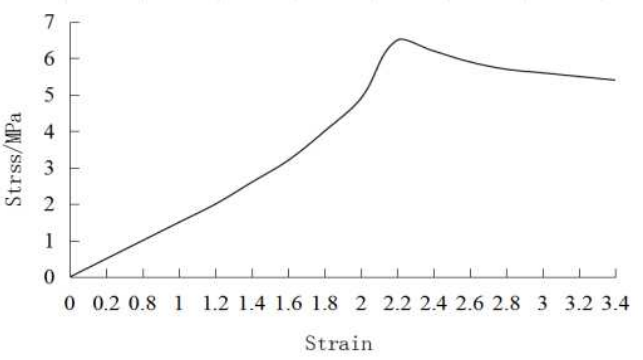

(d) Stress-strain curve of $28 \mathrm{~d}$ age

Fig. 5 Stress-strain curves at different ages 


\subsection{Analysis of microscopic properties}

Using the Hitachi S-4800 electron microscope, scanning electron microscopy (SEM) diagrams of the cemented material of the final formula at different ages were obtained to analyse the microscopic properties of cemented material with a large mass ratio of construction demolition waste, as shown in Fig. 6.

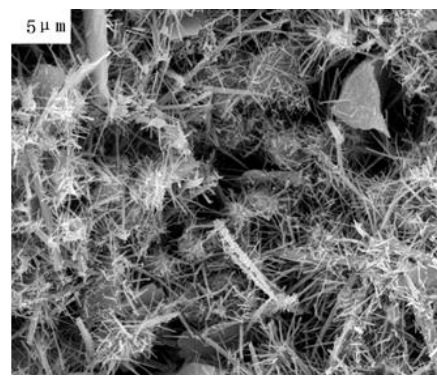

(a) Curing period of $8 \mathrm{~h}$

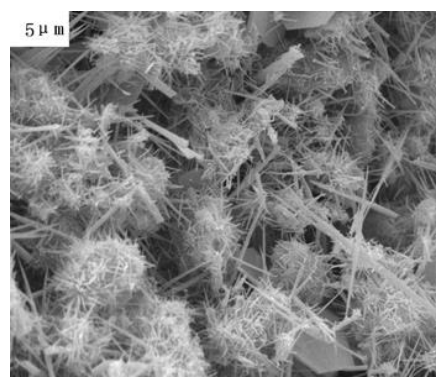

(b) Curing period of $3 \mathrm{~d}$

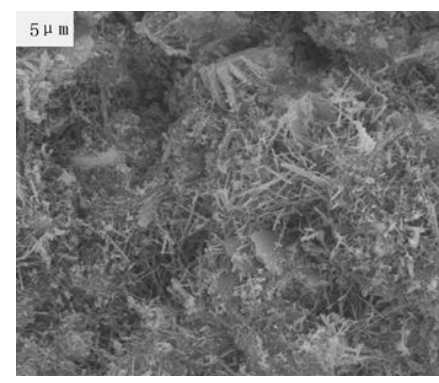

(c) Curing period of $28 \mathrm{~d}$

Fig. 6 SEM diagrams of cemented material with a large mass ratio of construction demolition waste at different ages

The hydration properties of the cemented material at different ages were studied for $8 \mathrm{~h}, 3 \mathrm{~d}$, and $28 \mathrm{~d}$. Through the SEM analysis, the cemented material results in a large number of fine cross and radial growth of needle-like ettringite after hydrating for $8 \mathrm{~h}$, which proves that the material basis for the early increase of the compressive strength of filling material is the continuous growth of ettringite. When the hydration reaction of the cemented material lasts for $3 \mathrm{~d}$, part of the needle-rod ettringite becomes coated with locally generated C-S-H (Calcium Silicate Hydrate) gel. When the hydration reaction of cemented material lasts for $28 \mathrm{~d}$, the ettringite is completely coated with gel, indicating that the material basis for the later increase in the compressive strength of the filling material is the continuous growth of gel. From the perspective of the microstructure of hydrate formation, the interlacing growth and coupling action of various hydrates promote the growth of the hardened body. Furthermore, there is no interaction and destruction because of the early or late formation of hydration products of different raw materials.

\section{Conclusions}

(1) The content of admixture is the decisive factor affecting the properties of cemented filling material with a large mass ratio of construction demolition waste. However, the aggregate/cement mass ratio, the water/solid mass ratio, the recycled aggregate gradation and the mud content of recycled aggregate also have a significant impact on the material performance.

(2) The compressive strength of the filling material is $2.5 \mathrm{MPa}$ for $7 \mathrm{~d}$, and the residual strength after yield is high at approximately $60 \sim 80 \%$ of the ultimate strength. Thus, the filling body exhibits good bearing capacity. The increase in strength of the filling material is attributed to the increase of ettringite content at the early stage and the continuous increase of C-S-H (Calcium Silicate Hydrate) gel at the later stage.

(3) Construction demolition waste accounts for $75 \%$ of the solid mass of the industrial formula of cemented filling material with a large mass ratio of construction demolition waste. Construction demolition waste provides a large number of raw materials for cemented filling material at lower costs, thus making it a promising candidate for such applications.

Acknowledgement This research was supported by the joint guiding project of the Natural Science Foundation of Heilongjiang Province of China (LH2019E119). 
Author's contributions $\mathrm{YB}, \mathrm{WC}$ and $\mathrm{YH}$ conceived the study and designed the experiment, $\mathrm{YB}$ wrote the manuscript and agreed to serve as the author responsible for contact to ensure communications. WC performed the experiment and analyzed the data. WC and YH reviewed and revised the manuscript.

Conflict of interest The authors declare that they have no conflict of interests.

\section{References}

Kang HP, Xu G, Wang BM, et al (2019) Forty years development and prospects of underground coal mining and strata control technologies in China. Journal of Mining and Strata Control Engineering 1(1):013501.

Wang GF (2013) Innovation and development of safe, high-efficiency and green coal mining technology and equipments. Coal Mining Technology 18(5):1-5

Hu BN (2012) Backfill mining technology and development tendency in China coal mine. Coal Science and Technology 40(11):1-5,18

Jia KJ, Feng GM (2012) Backfill mining technology with ultra high water material in coal mine and outlook. Coal Science and Technology 40 (11) :6-9,23

Yang BG, Yang J (2015) Development and selection on filling technology of coal mine. Mining Research and Development 35(5):11-15

Cheng K, Yang BG, Zhang BG, et al (2018) Present situation and development direction of filling mining technology in coal mines in China. Coal Technology 37(03):73-76

Liu JG, Li XW, He T (2020) Application status and prospect of backfill mining in Chinese coal mines. Journal of China Coal Society 45(1):141-150

Li ZH (2018) Discussion on the present situation and development suggestions of the utilization of construction waste resources in China. China Resources Comprehensive Utilization 36(10):74-77

Wang XG, He TS, Zhang KF, et al (2018) Research status of construction waste recycling technology. Beton Chinese Edition — Ready-mixed Concrete (10):34-36,41

Huang B, Wang X, Kua H, Geng Y, Bleischwitz R, Ren J (2018) Construction and demolition waste management in China through the $3 \mathrm{R}$ principle. Resources, Conservation and Recycling 129: 36-44. https://doi.org/10.1016/j.resconrec.2017.09.029

Lu HL (2018) Analysis of the problem and outlet of China's construction waste. environment and sustainable development 43(3): 45-48

Xu YB, Li Y, Fan B (2019) The current situation, problems and suggestions of construction waste recycling industry in China. Wall Materials Innovation and Energy Saving in Building (12) 56-59.

Chen Q, Zhang Q, Qi C, Fourie A, Xiao C (2018) Recycling phosphogypsum and construction demolition waste for cemented paste backfill and its environmental impact. Journal of Cleaner Production 186:418-429. https://doi.org/10.1016/j.jclepro.2018.03.131

Liu Y, Chen JT, Liu JX, et al (2012) Advance of filling paste into mine goaf with building waste. Journal of Shandong University of Science and Technology (Natural Science) 31(6):52-56

Liu Y, Lu Y, Guo H, et al (2017) Experimental study on proportion optimization of construction waste paste filling materials. Safety in Coal Mines 48(6):65-68

Zhang HQ, Liu Y, Wang QF (2014) Study on performance of paste filling with urban construction waste. Mining Research and Development 34(4):37-39,54

Zhang BL, Liu Y, Zhang HQ, et al (2014) Round-pipe experiment of filling paste with recycled 
aggregate of building waste. Metal Mine (2):176-180

Jiang MY, Li TC, Li Z, et al (2015) Orthogonal test study on the preparation of filling paste with construction waste aggregate. Bulletin of the Chinese Ceramic Society 34(10):2948-2953

Chen WX (2015) Experimental study on construction waste-fly ash-based cement filling material. Journal of Heilongjiang University of Science and Technology 25 (6): 637-640

Qiu WC, Wang FG, Liu SJ, et al (2016) Effect of particle size on the strength of construction waste slurry backfill material. Journal of Shandong University of Technology (Natural Science Edition) 30(6):40-43,47

Han YF, Yin ZX, Guo BL (2018) Experimental study on basic properties of building waste filling paste. Mining Research and Development 38(3):88-90

Li H, Liu Y, Wang K, et al (2019) Experimental study on physical properties of construction waste aggregate-coarse fly ash-based cement filling. Safety in Coal Mines 50(12):60-63

Liu HF, Zhang JX, Zhou N, Guo YM, Li BY, Yan H, Deng XJ (2020) Investigation of spatial stratified heterogeneity of cemented paste backfill characteristics in construction demolition waste recycled aggregates. Journal of Cleaner Production 249: 119332. https://doi.org/10.1016/j.jclepro.2019.119332

Chen WX, Fu MC, Liu SM, et al (2014) Experiment on mining using bag strip filled with fly ash-based cements. Journal of Heilongiiang University of Science and Technology 24(4): 360-363

Chen WX, Li FY, Hu G, et al (2015) Experimental study on early strength agent of fly ash-based cement filling material. Journal of Heilongjiang University of Science and Technology 25(3): $267-268$

Chen WX, Li FY (2015) Experimental research on the basic performance of fly-ash-based cement filling material. Journal of Heilongjiang University of Science and Technology 25(4): 375-380

Chen WX, Li FY, Shan QY (2019) Rheological properties behind fly-ash-based cement filling material. Journal of Heilongjiang University of Science and Technology 29(1): 105-109

Sun HH, Huang YC, Yang BG (2002) Contemporary cementing filling technique. Metallurgical Industry Press, Beijing

Huang YC (2014) Theory and technology of mine filling. Metallurgical Industry Press, Beijing

Yang BG (2015) Mining technology of high concentration cemented filling in coal mine. Coal Industry Press, Beijing 
Figures

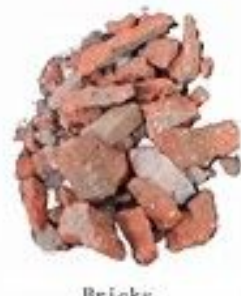

Bricks

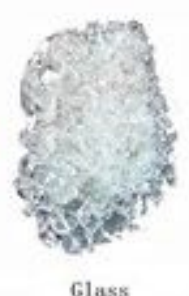

Glass

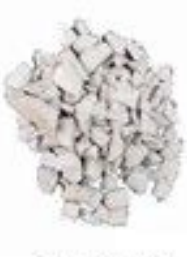

Ceranic tile

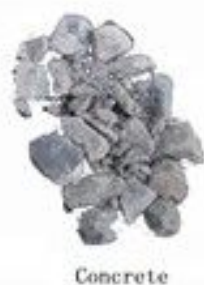

Concrete

\section{Figure 1}

The recycled aggregate of construction demolition waste

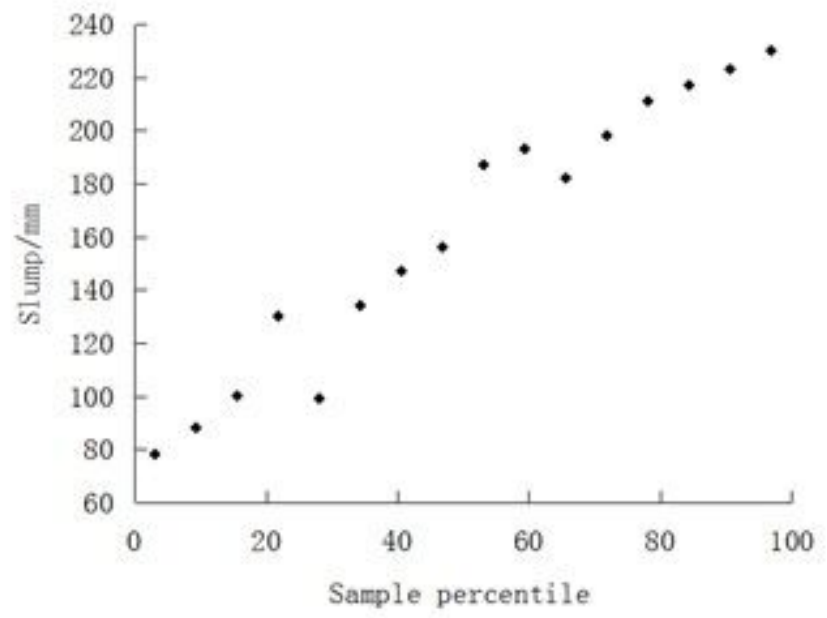

Figure 2

Normal probability distribution diagram of the slump of the initial slurry

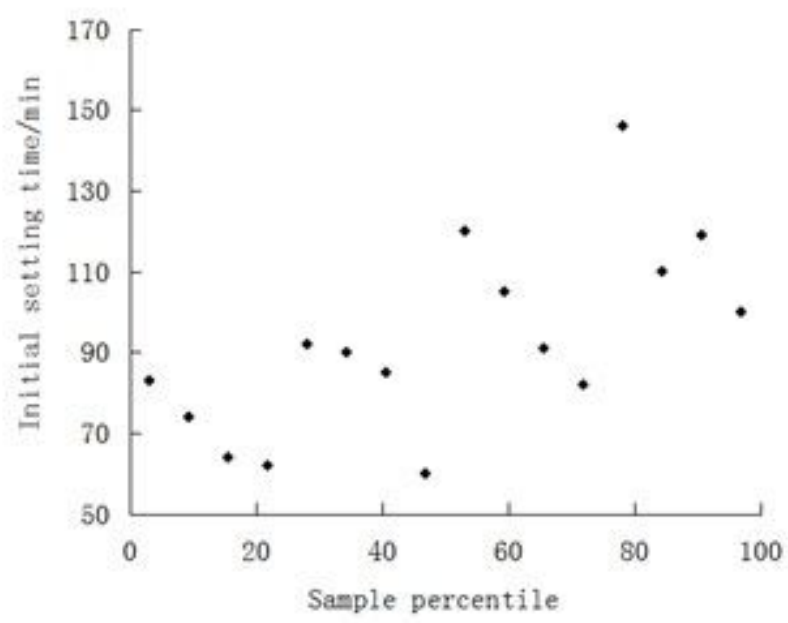

Figure 3 
Normal probability diagram of initial setting time

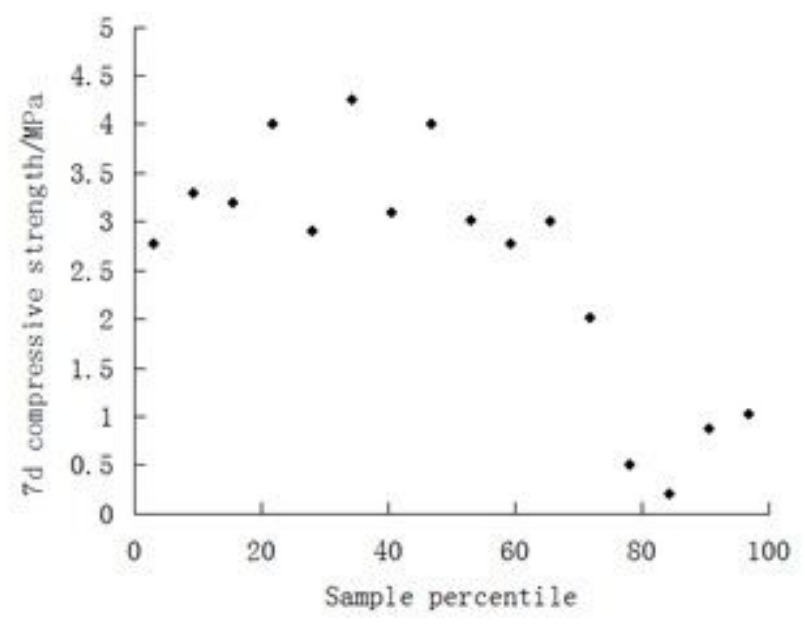

\section{Figure 4}

Normal probability diagram of compressive strength for $7 \mathrm{~d}$

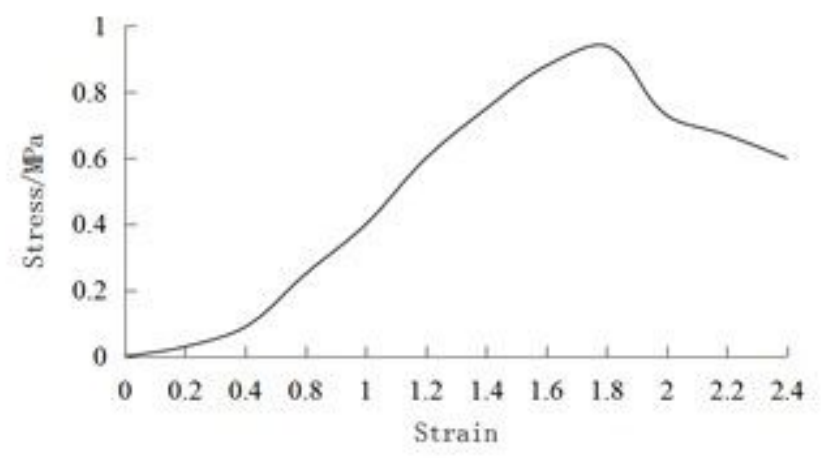

(a) Stress-strain curve of $1 \mathrm{~d}$ age

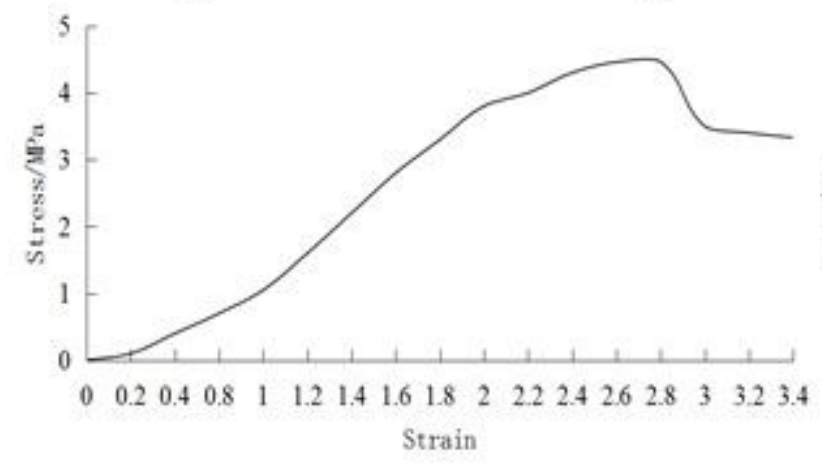

(c) Stress-strain curve of $14 \mathrm{~d}$ age

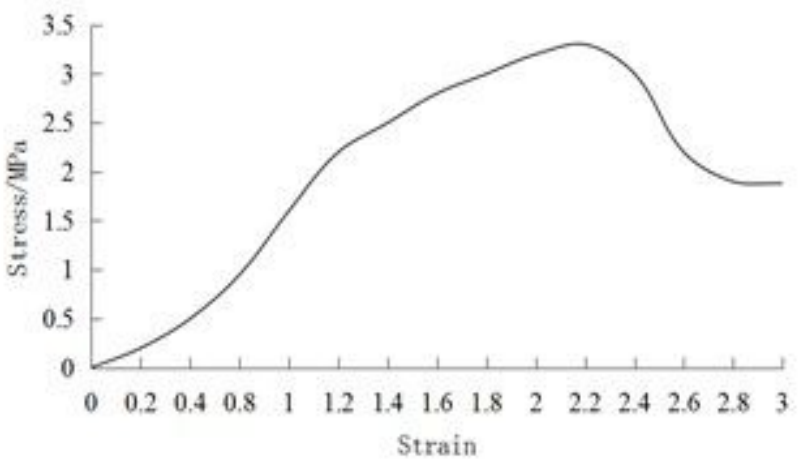

(b) Stress-strain curve of $7 d$ age

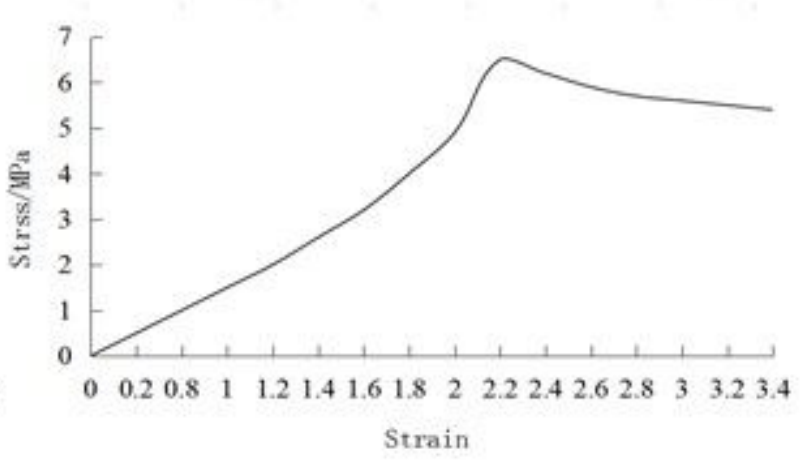

(d) Stress-strain curve of $28 \mathrm{~d}$ age

\section{Figure 5}

Stress-strain curves at different ages 


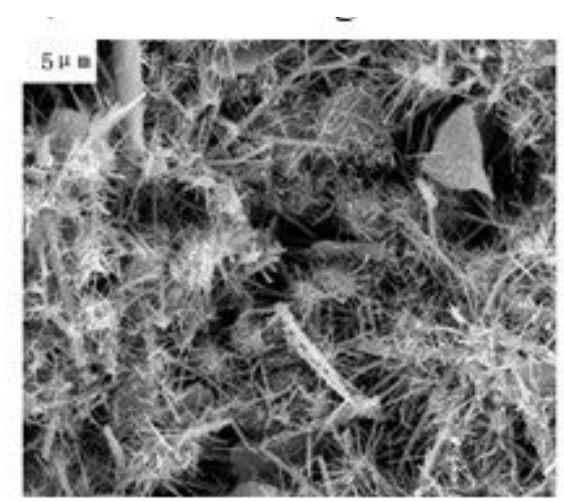

(a) Curing period of $8 \mathrm{~h}$

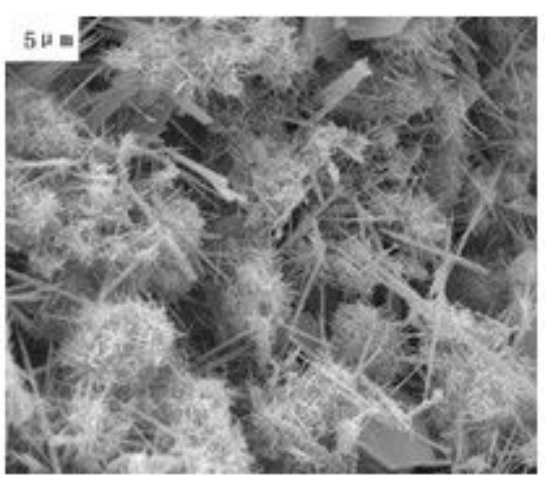

(b) Curing period of $3 \mathrm{~d}$

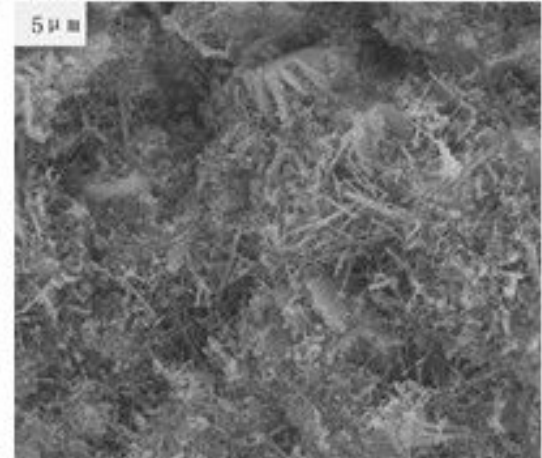

(c) Curing period of $28 \mathrm{~d}$

\section{Figure 6}

SEM diagrams of cemented material with a large mass ratio of construction demolition waste at different ages 